\title{
Advice About Life Plans and Personal Problems in Late Adolescent Sibling Relationships
}

\author{
Corinna Jenkins Tucker, ${ }^{1}$ Bonnie L. Barber, ${ }^{2}$ and Jacquelynne S. Eccles ${ }^{3}$ \\ Received October 30, 1995; accepted February 23, 1996
}

This study examined older adolescents' perceptions of the following sibling relationship characteristics: advice about life plans and personal problems, satisfaction with support, and sibling influence on interests and goals. Little is known about late adolescent sibling relationships and siblings' role in the identity formation process. Differences between first- and secondborns, males and females, and opposite- and same-gender sibling pairs were explored. Participants were 223 adolescents ( $\mathrm{M}=17.5$ years old) who filled out a survey in their senior year of high school. All adolescents were from always-married families and had one sibling between the ages of 13 and 23. Analyses revealed that both secondborns and females reported receiving more advice, being more satisfied with sibling support, and being influenced more by their sibling than firstborns and males, respectively. In addition,

This research was supported by grants from the National Science Foundation (DBS9215008) to Barber and Eccles, (92-1459-92) from the William T. Grant Foundation to Eccles and Barber, and by a Spencer Foundation grant to Eccles and Barber.

${ }^{1}$ Doctoral student, Human Development and Family Studies Department, S-110 Henderson Building South, The Pennsylvania State University, University Park, Pennsyivania 16802. Received M.S. from The Pennsylvania State University. Research interests include children's and adolescents' sibling relationships, family influences on social development and well-being, family relationships in always-married and divorced families, and gender roles. To whom correspondence should be addressed.

${ }^{2}$ Associate Professor, Family Studies Department, University of Arizona, Tucson, Arizona, Received Ph.D. in Developmental Psychology from The University of Michigan. Research interests include family influences on adolescent identity development, and risk, resilience, and preventative intervention for adolescents and mothers in divorced and remarried families. ${ }^{3}$ Professor, Psychology Department, The University of Michigan, Ann Arbor, Michigan. Received Ph.D. in Psychology from the University of California at Los Angeles. Research interests include social development, identity development, contextual influences on development, and gender and ethnicity.

63 
those in female-female sibling pairs received more advice from their siblings than those in male-male and mixed gender pairs. Findings revealed that adolescents do sometimes rely on their siblings as a source of advice about life plans and personal problems.

\section{INTRODUCTION}

The nature of sibling relationships changes as children and adolescents grow older. At present, most of the information on sibling experiences has come from younger children's relationships (e.g., Bryant and Crockenberg, 1980; Dunn and Kendrick, 1982; Dunn and Munn, 1986) or later in the life span (e.g., Cicirelli, 1982). More recently, researchers have begun to focus on sibling relationships in adolescence (e.g., Stocker and Dunn, 1994). However, research on adolescent sibling relationships has focused predominantly on early and middle adolescence, and therefore little is known about sibling experiences in late adolescence.

Much of the information on late adolescent sibling experiences has derived from cross-sectional studies examining the changing nature of sibling experiences from childhood through adolescence. Investigations have found that as children grow older, the amount of affection and companionship between siblings decreases (Furman and Buhrmester, 1985; Buhrmester and Furman, 1990). Buhrmester (1992) has proposed that a decrease in warmth and disclosure between siblings in adolescence parallels the developmental course of teenagers' relationships with their parents and their increased involvement outside the family. However, this decrease should not be interpreted as meaning that siblings do not remain important in each other's lives during adolescence. Reports of the absolute levels of disclosure and companionship with siblings reveal that these remain relatively high (Buhrmester, 1992; Stocker and Dunn, 1994) and that siblings are still primary sources of emotional support in late adolescence (Lamb, 1982).

During adolescence, identity formation is an ongoing process. Older adolescents must make important job, family, and education plans. At present, we know something about parent-adolescent discussion of life plans (Hunter, 1985; Barber, 1994). We know nothing about the role of siblings, however, in the identity formation process. Because adolescence is a time when parents and children may have difficulty communicating about emotionally laden issues, an adolescent may find it easier to talk with a sibling than with a parent (Lamb, 1982). Adolescents may want advice from someone with whom they have a long and established relationship, someone who may hold similar values, and someone who can serve as a testing ground for ideas before they are discussed with parents. 
Sibling experiences may vary by the gender of the adolescent, birth order, or sibling gender constellation. Past studies focusing on the impact of these status variables on sibling relationships in preschool or early childhood have shown few links or inconsistent results (Dunn, 1988; Furman and Buhrmester, 1985; Stoneman et al., 1984). It is not known, however, whether gender of the adolescent, birth order, and gender composition of the sibling dyad are important in adolescence. Buhrmester (1992) has criticized the research on sibling relationships, arguing that the importance of sibling constellation variables as inportant predictors of sibling experiences has not been emphasized. To address this, the present study examined whether older adolescents' perceptions of three sibling relationship characteristics: (1) advice about life plans and personal problems, (2) satisfaction with support from sibling, and (3) siblings' influence on interests and goals, differed by adolescent gender, birth order and gender composition of the sibling dyad.

\section{Birth Order and Sibling Relationship Characteristics}

Within the sibling dyad, individual perceptions of the relationship are not always congruent. Older and younger siblings likely have different perceptions of their relationship (Dunn, 1992). Buhrmester (1992) provided evidence that older and younger siblings' perceptions of the level of confliction their relationships differed, with increased divergence in adolescence. Older siblings viewed their younger siblings as an annoyance, while younger siblings reported greater intimacy and more admiration for their older siblings. In addition, older siblings' reports of antagonism with their younger siblings showed a slight increase, whereas younger siblings perceived the rate of conflict as declining.

A relationship with an older sibling may have important consequences for a younger sibling. Studies have demonstrated that older siblings often serve as guides or teachers for younger siblings (Dunn and Kendrick, 1982; Klagsbrun, 1992; Vandell et al, 1987). In addition, research indicates that older siblings are often more likely to influence younger siblings than to be influenced by them (e.g., Bryant, 1982; Newman, 1991; Rogers and Rowe, 1988). In late adolescence, older siblings may act as a guide and give advice about life plans and personal problems to younger siblings. Older siblings may be viewed as an important source of support and knowledge by younger siblings and have influence on younger siblings' goals and interests. Decisions regarding school, family, and career plans will generally be made by older siblings before younger siblings, and therefore older siblings may be viewed as an influential resource for these types of decisions. This hierarchical quality, or complementary feature (Dunn, 1983), of sibling relationships may be especially true with issues of developmental significance because older siblings generally experience developmental tasks before younger siblings do. 


\section{Adolescent Gender and Sibling Relationship Characteristics}

How the gender of the adolescent influences sibling relationship experiences is often not emphasized or is ignored (see Buhrmester, 1992). Buhrmester (1992) found a trend suggesting that adolescent girls reported greater intimacy with siblings than did boys. Findings from another study suggest that girls viewed their sibling relationships as more supportive than boys (Furman and Burhmester, 1992). This difference is consistent with social psychologists' research findings that females may be more competent at exchanges involving intimate disclosure (Reis, 1986; Wheeler et al., 1983). Adolescent gender is therefore likely to influence adolescents' perceptions of the three sibling relationship characteristics examined in the present study: advice about life plans and personal problems, satisfaction with support, and siblings' influence on interests and goals. For example, females may report more satisfaction with support from their siblings than males.

\section{Sibling Gender Constellation and Sibling Relationship Characteristics}

Sibling gender constellation may have increasing developmental importance for sibling relationships. In preschool and early childhood there is little evidence of an association between gender constellation and the quality of sibling relationships. Recent studies of middle childhood, however, reveal that the gender composition of the sibling dyad is linked to the exchange of intimate disclosures. During middle childhood intimate disclosure is most common in same-gender sibling dyads (Buhrmester, 1992; Furman and Buhrmester, 1985). Similar results have been found in studies of young adolescents' perceptions of the sibling relationship (Bowerman and Dobash, 1974; Buhrmester and Furman, 1990). This pattern is likely to continue into late adolescence and the content of intimate disclosure may include developmentally relevant issues such as seeking advice about life plans and personal problems, but to date no studies have focused on this question. Adolescents from same gender-sibling dyads may receive more advice from their siblings than adolescents from opposite-gender sibling dyads. Also, it may be that the greater self-disclosure between samegender sibling pairs may be associated with adolescents reporting more satisfaction with support from their siblings and greater sibling influence than adolescents from opposite-gender sibling pairs. 


\section{Summary}

The sibling relationship is an important one and the nature of sibling experiences changes as children grow older. Little is known, however, about older adolescents' sibling experiences. Older adolescents may rely on their siblings for advice concerning decisions about career, family and education plans, and personal problems. Birth order, gender of the adolescent, and the presence of a same- or opposite-gender sibling have all been linked to children's and adolescents' perceptions of particular domains of the sibling relationship. However, research on these potential moderators of siblings' experiences have generally focused on younger children's sibling relationships. Different birth order position, gender of the adolescent, and the presence of an opposite- or same-gender sibling may be associated with different experiences in the areas of receipt of sibling advice, satisfaction with support from a sibling, and sibling influence.

\section{METHOD}

Data were drawn from the sixth wave of the Michigan Study of Adolescent Life Transitions (MSALT). These data were collected in 1990 when participants were seniors in high school. MSALT began in 1983, when the students were making the transition from the sixth to the seventh grade (for recruitment and attrition information, see Eccles et al., 1989). The study was designed to investigate normative and nonnormative transitions during adolescence.

\section{Participants}

The participants were from nine predominately white middle and lower middle class school districts in southeastern Michigan. The samme's socioeconomic characteristics were representative of the families in the selected school districts. The ethnic diversity of the sample was limited; $87 \%$ identified themselves as Caucasian, $7 \%$ as African American, $1 \%$ as Asian, $1 \%$ as Latino, and $2 \%$ as Native American (Clark and Barber, 1994). The ages of the participants at the sixth wave ranged from 16 to 19 ; the modal age (47\% of the sample) was 17. 
At the sixth wave, 1351 adolescents completed the survey. Of the 1351 students responding at the sixth wave, 966 reported that their parents were married and living together. ${ }^{4}$ Twenty-five adolescents in always-married families whose parents had been married less than 15 years were excluded from the sample.

The sample was further limited based on sibling constellation requirements. Those excluded were 227 adolescents with more than one sibling or no siblings. Because some sibling relationship questions were about all the siblings in the family and not restricted to a particular sibling and because it was not possible to discern which siblings the adolescents were describing, only adolescents with one sibling were included. Eighty-one adolescents whose sibling was not between 13 and 23 years of age were excluded. The age of the sibling was restricted to a five- to six-year interval because the focus of this study was adolescent siblings and the nature of the sibling relationship characteristics being examined. For example, siblings less than 13 years of age would likely have little or no influence on an older adolescent's life plans. Nine pairs of twins also were excluded because this study examined birth order effects. Therefore, the final sample included 223 adolescents who reported their parents were married and living together throughout the adolescents' lives.

\section{Procedures}

Students were asked to fill out a 57-page questionnaire containing approximately $\mathbf{7 5 0}$ items one month prior to the end of the students' senior year of high school. All of the subjects who participated were given 90 minutes to complete the questionnaire in their school cafeterias while research staff members were present to answer questions. Questionnaires and postage-paid return envelopes were mailed to students who had participated in previous waves of data collection but were absent on the day of the survey.

\footnotetext{
${ }^{4}$ Separate analyses revealed no differences between adolescents' reports from divorced and always-married families. In addition, there were no significant interactions of either birth order or gender by family structure (Jenkins, 1995). The cell sizes in divorced families were too smail to conduct analyses for gender composition. To maintain the clarity of the paper, only always-married families were included.
} 


\section{Measures}

The questionnaire covered a broad range of topics including the students' beliefs, values, and attitudes about self, and the nature of their relationships with parents, siblings, peers, and adults outside the family.

\section{Family Structure}

Respondents were asked to check the marital status of their biological ("natural") parents. Students who reported that their parents were "married and living together" and that this had been their parents' marital status for more than fifteen years were included. Respondents were asked to check the number of siblings living inside and outside their home.

Birth Order

Respondents were asked to indicate whether they had a brother or a sister. The respondent's birth order in relation to the sibling was determined by comparing the age of the respondent to the age of the sibling.

\section{Advice About Life Plans and Personal Problems}

One section of the questionnaire contained a series of seven items about advice from siblings: (1) "My sibling(s) and I talk about my future job and educational plans"; (2) "My sibling(s) and I talk about my future family plans"; (3) "My sibling(s) and I talk about my personal problems"; (4) "Talks with my sibling(s) have helped me to make educational plans after high school"; (5) "Talks with my sibling(s) have helped me to make job plans"; (6) "Talks with my sibling(s) have helped me to make family plans"; and (7) "Talks with my sibling(s) have helped me to solve personal problems." The interval scale for the first three items ranged from 1 (Never) to $7(A$ lot $)$ and the interval scale for the last four items ranged from $1(A$ little) to $7(A$ lot $)$. A mean of the seven items was computed for an index of advice on life plans and personal problems $(M=3.13, S D=1.67)$. The Cronbach's alpha for the composite was .95 . 


\section{Satisfaction with Support}

Satisfaction with support from a sibling was measured by one item rated on a seven-point scale: (1) "How satisfied are you with the emotional support you get from your sibling(s)?" The range of the interval scale for the item was from 1 (Not at all satisfied) to 7 (Very satisfied; $M=4.33, S D=1.92$ ).

\section{Sibling Influence}

Siblings' influence on the respondents' interests and goals was measured by one item: "How much influence has your sibling had on your interests and goals?" The interval scale ranged from 1 ( $A$ little) to 7 ( $A$ lot); $M=3.35, S D=1.86$.

\section{RESULTS}

Multivariate analyses of variance (MANOVA) were used to examine birth order, gender, and gender constellation differences in the three sibling relationship characteristics: advice about life plans, satisfaction with support, and sibling influence. Due to unequal cell sizes, Type III sums of squares were used in all analyses (Lewis and Kiren, 1977). When the overall MANOVA was significant, follow-up univariate tests analyzed the source of the multivariate effects (see Tables I-III).

The first MANOVA examined birth order differences in the three sibling relationship characteristics. ${ }^{5}$ The omnibus test was significant indicating first- and second-born children have different sibling relationship experiences (Wilkes criterion $=.90), F(3,203)=7.38, p<.001$. Univariate tests revealed second-borns received more advice, were more satisfied with support from siblings, and were influenced more by their older siblings (see Table I.)

A second MANOVA investigated sibling relationship differences by the gender of the reporting adolescent. A significant multivariate effect was revealed (Wilkes criterion $=.94), F(3,203)=4.05, p<.01$. Follow-up univariate tests indicated that females reported getting more advice, being more satisfied with support, and being influenced more by their siblings than males (see Table II).

\footnotetext{
${ }^{5}$ Age spacing of the sibling pairs was considered. Analyses of siblings spaced two or less years apart were contrasted with siblings spaced three or more years apart. The $2 \times 2$ analysis of variance examing age spacing and birth order effects was not significant.
} 
Table I. Multivariate Analyses of Sibling Relationship Characteristics by Birth Order

\begin{tabular}{lccc}
\hline & $\begin{array}{c}\text { Older Siblings } \\
(n=106)\end{array}$ & $\begin{array}{c}\text { Younger Siblings } \\
(n=101)\end{array}$ & $F$ Statistic \\
\hline Advice & $2.68(1.37)$ & $3.66(1.84)$ & $19.00^{b}$ \\
Satisfaction with support & $4.11(1.67)$ & $4.67(2.04)$ & $4.69^{a}$ \\
Sibling influence & $2.84(1.57)$ & $3.89(2.00)$ & $17.81^{b}$ \\
\hline
\end{tabular}

$a_{p}<.05$.

${ }^{b} p<.001$.

A third MANOVA revealed differences by sibling gender constellation (Wilkes criterion $=.92), F(3,203)=2.69, p<.01$. Univariate analyses showed significant effects for advice and satisfaciion with support. Follow-up Newman-Keuls tests indicated that adolescents from female-female sibling pairs received more advice from their siblings than male-male and mixedgender sibling pairs. No significant pairwise comparisons emerged between different gender constellations of the sibling dyad for satisfaction with support (see Table III).

\section{DISCUSSION}

The present study demonstrated that older adolescents sometimes rely on their siblings as a source of advice about life plans and personal problems. For example, adolescents reported mean levels of advice ranging from 2.5 to 4.0 on a 7-point scale. Previous findings have demonstrated that adolescent siblings tend to disclose less to each other than at earlier ages (Buhrmester, 1992). These findings, however, suggest that talking about life plans and personal problems is an important dimension of sibling relationships in late adolescence.

Table II. Multivariate Analyses of Sibling Relationship Characteristics by Adolescents' Gender

\begin{tabular}{lccc}
\hline & Females & Males & \\
& $(n=112)$ & $(n=95)$ & $F$ statistic \\
\hline Advice & $3.52(1.67)$ & $2.72(1.61)$ & $12.22^{c}$ \\
Satisfaction with support & $4.66(1.89)$ & $4.06(1.82)$ & $5.32^{a}$ \\
Sibling influence & $3.65(1.81)$ & $3.00(1.87)$ & $6.46^{b}$ \\
\hline
\end{tabular}

$a p<.05$.

${ }^{b} p<.01$.

${ }^{c} p<.001$. 
Table III. Multivariate Analyses of Sibling Relationship Characteristics by Sibling Gender Constellation

\begin{tabular}{lcclc}
\hline & $\begin{array}{c}\text { Female pairs } \\
(n=47)\end{array}$ & $\begin{array}{c}\text { Male pairs } \\
(n=33)\end{array}$ & $\begin{array}{c}\text { Mixed pairs } \\
(n=127)\end{array}$ & $F$ statistic \\
\hline Advice & $3.96(1.63)_{\mathrm{a}}$ & $2.96(1.74)_{\mathrm{b}}$ & $2.91(1.61)_{\mathrm{b}}$ & $7.36^{c}$ \\
Satisfaction with support & $5.02(1.65)$ & $4.36(1.95)$ & $4.16(1.90)$ & $3.74^{b}$ \\
Sibling influence & $3.83(1.88)$ & $3.36(2.01)$ & $3.17(1.80)$ & 2.15 \\
\hline
\end{tabular}

${ }^{a}$ Means with different subscripts differ significantly at $p<.01$ by the Newman-Keuls test.

${ }^{b} p<.05$.

${ }^{c} p<.001$.

This study examined three characteristics of older adolescent sibling relationships in always-married families but future studies could explore if similar patterns for the three sibling relationship characteristics are evident across family contexts. For example, expanding on the work of Barber (1994), an examination of siblings in divorced families could investigate whether adolescents' relationships with their noncustodial fathers are related to adolescents seeking advice from their siblings. Barber (1994) found great variability in the frequency with which adolescents from divorced families had contact with their fathers. It might be fruitful to investigate whether adolescents with little contact with their fathers depended on their older siblings more often for advice about life plans and personal problems.

On a related note, Fuligni and Eccles (1993) found that when adolescents were not satisfied with their relationship with their parents, they tended to be more peer oriented and sought more advice about personal and future issues from their peers than from their parents. In addition to increasing peer orientation, unsatisfying parent-child relationships may be related to adolescents' seeking more advice from their siblings. It has been proposed that a poor relationship with an adult will be compensated for by a close relationship with a sibling (Bank and Kahn, 1982a,b). Bryant and Crockenberg (1980) reported an increase in sibling prosocial behavior between sisters when their mothers ignored them. On the other hand, some researchers have argued that there is a positive association between parent-child and sibling relationships. Studies have found support for a congruence hypothesis indicating, for example, that positive parent-child relationships are linked to positive sibling relationships (Bryant and Crockenberg, 1980). Bryant and Crockenberg's study (1980) demonstrated that sibling relationships can have both compensatory and congruent characteristics. Whether adolescents are more or less likely to turn to their siblings for advice when they have a poor parent-child relationship is an important area for future study. 
Birth Order and Sibling Relationship Experiences

A goal of this study was to investigate whether firstborn and secondborn siblings had different sibling relationship experiences. Buhrmester (1992) has shown that siblings of different birth orders have different perceptions of the level of conflict between then and different tendencies to confide in a sibling. Consistent with Buhrmester's work, differences were found in firstborn and secondborn siblings' perceptions of getting advice from siblings, satisfaction with support and siblings' influence. In all three instances, secondborn siblings perceived higher levels.

The differences between firstborn and secondborn siblings' perceptions of advice and siblings' influence suggest a power or status structure in the sibling relationship. Past studies, however, indicate that sibling relationships become more egalitarian and less asymmetrical with age (Buhrmester and Furman, 1990; Vandell et al., 1987). Buhrmester and Furman (1990) suggested that the relative difference between siblings in power decreases as younger siblings become "more competent and independent" (p. 1395). Though the present study was not longitudinal, it is clear that for the domains of sibling advice about life plans and personal problems and sibling influence a hierarchical relationship was perceived between siblings in late adolescence. Perhaps, with issues of developmental significance younger siblings seek nurturance and direction from older siblings. Secondborn siblings may rely on their older siblings for advice about life plans and personal problems because older siblings may be more likely to have the experience and resources to provide younger siblings with advice and emotional support. Older siblings may have more influence on younger siblings, because younger siblings view older siblings as an informed source of information about life plans and personal problems. Longitudinal data would provide the opportunity to discern patterns of stability and change that may characterize adolescents' sibling relationship experiences. For example, analyses of longitudinal data could provide insight into patterns of advice giving between siblings. The exchange of certain kinds of advice between siblings may be related to the increasing egalitarian quality of sibling relationships as children grow older. Furthermore, the results of sibling influence must be regarded with some caution, as the construct of influence on interests and goals was measured with a single item. Future studies should consider additional domains of and paths toward sibling influence in late adolescence. 


\section{Adolescent's Gender and Sibling Relationship Experiences}

Females reported more advice from a sibling, more satisfaction with support, and greater sibling influence. Gender differences in sibling relationship experiences may be related to females being more competent at intimate exchanges (Reis, 1986; Wheeler et al., 1983). Females also have been found to report greater intimacy with their siblings than males do (Buhrmester, 1992). Because males are less skilled at intimate exchanges and are less likely to discuss feelings and issues with their siblings, males may be less likely to seek advice from a sibling. Males also may get lower quality of advice from their siblings. These differences may account for males reporting lower satisfaction with support from their siblings and lower amounts of sibling influence than females.

\section{Sibling Gender Constellation and Sibling Relationship Experiences}

Female-female sibling pairs reported getting more advice than male-male or mixed-gender sibling pairs in this study. Studies of young adolescent siblings have shown that intimate disclosure is more common in same gender pairs (Bowerman and Dobash, 1974; Furman and Buhrmester, 1990). Similar results have been found for adolescent siblings' feelings of warmth and closeness (Bowerman and Dobash, 1974; Buhrmester and Furman, 1990; Furman and Buhrmester, 1985). Perhaps adolescents from female-female sibling pairs are more intimate and, therefore, can relate to the experiences of each other more easily than adolescents from male-male and opposite-gender sibling pairs.

Though the intensity of sibling relationships decreases with age (Buhrmester and Furman, 1990; Buhrmester, 1992), siblings still play an important role in each others' lives. Therefore, more research should explore older adolescent sibling relationship experiences. Future research, however, on sibling relationships should continue to incorporate a developmental framework. In addition, future examinations of various family processes associated with different sibling relationship experiences should continue to take into account birth order, gender of the respondent, and sibling gender constellation. Finally, this study examined only one sibling's view about experiences in the sibling dyad because the second sibling was not a participant in the larger longitudinal study (MSALT). Future research should include both siblings' reports of their relationship. Having each members' report of the sibling dyad would provide opportunities to examine both agreements and discrepancies in siblings' perceptions of their relationship. 


\section{ACKNOWLEDGMENTS}

We gratefully acknowledge the assistance of Lisa Colarossi, Andrew Fuligni, Debra Jozefowicz, Laurie Meschke, and Patricia Wamboldt for their contributions to data collection, coding, and management. We would also like to thank Susan McHale for her helpful comments on earlier drafts.

\section{REFERENCES}

Bank, S. P., and Kahn, M. D. (1982a). The Sibling Bond. New York, Basic Books.

Bank, S., and Kahn, M. (1982b). Intense sibling loyalties. In Lamb, M. E., and Sutton-Smith, B. (eds.), Sibling Relationships. Erlbaum, Hillsdale, NJ.

Barber, B. L. (1994). Support and advice from married and divorced fathers: Linkages to adolescent adjustment. Family Relat. 43: 433-438.

Bowerman, B. K., and Dobash, R. M. (1974). Structural variations in inter-sibling affect. $J$. Marriage Family, 36: 48-54.

Bryant, N. (1982). Sibling relationships in middle childhood. In Lamb, M. E., and Sutton-Smith, B. (eds.), Sibling Relationships: Their Nature and Significance Across the Lifespan. Erlbaum, Hillsdale, NJ.

Bryant, N., and Crockenberg, S. (1980). Correlates and dimensions of prosocial behavior: A study of female siblings with their mothers. Child Develop. 51: 529-5:4.

Buhrmester, D. (1992). The developmental courses of sibling and peer relationships. In Boer, F., and Dunn, J. (eds.), Children's Sibling Relationships: Developmental an''Clinical Issues. Erlbaum, Hillsdale, NJ.

Buhrmester, D., and Furman, D. (1990). Perceptions of sibling relationships during middle childhood and adolescence. Child Develop. 61: 1387-1398.

Cicirelli, V. C. (1982). Sibling influence throughout the lifespan. In Lamb, M. E., and Sutton-Smith, B. (eds.), Sibling Relationships: Their Nature and Significance Across the Lifespan. Erlbaum, Hillsdale, NJ.

Clark, J., and Barber, B. L. (1994). Adolescents in postlivorce and always-married families: Self esteem and perceptions of fathers' interest. J. Marriage Family 56: 608-614.

Dunn, J. (1983). Sibling relationships in early childhood. Child Develop. 54: 787-811.

Dunn, J. (1988). Annotation: Sibling influences on childhood development. J. Child Psychol. Psychiat. 29: 119-127.

Dunn, J. (1992). Sisters and brothers: Current issues in developmental research. In Boer, F., and Dunn, J. (eds.), Children's Sibling Relationships: Developmental and Clinical Issues. Erlbaum, Hillsdale, NJ.

Dunn, J., and Kendrick, C. (1982). Siblings: Love, Envy, and Understanding. Grant McIntrye, London.

Dunn, J., and Munn, P. (1986). Siblings' quarrels and maternal intervention: Individual differences in understanding and aggression. J. Child Psychol. Psychiat. 27: 583-595.

Eccles, J. S., Wigfield, A., Flanagan, C. A., Miller, C., Reuman, D. A., and Yee, D. (1989). Self-concepts, domain values, and self-esteem: Relations and changes at early adolescence. J. Personal. 57: 283-310.

Fuligni, A. J., and Eccles, J. S. (1993). Perceived parent-child relationships and early adolescents' orientation toward peers. Develop. Psychol. 29: 622-632.

Furman, W., and Buhrmester, D. (1985). Children's perceptions of the qualities of sibling relationships. Child Develop. 56: 448-461.

Hunter, F. T. (1985). Adolescents' perceptions of discussions with parents and friends. Develop. Psychol. 21: 433-440. 
Jenkins, C. J. (1995). Older adolescent sibling relationships in divorced and always-maried families. Unpublished master's thesis, Pennsylvania State University.

Klagsbrun, F. (1992). Mixed Feelings: Love, Hate, Rivaly, and Reconciliation Among Brothers and Sisters. New York, Bantam Books.

Lamb, M. E. (1982). Sibling relationships across the lifespan: An overview and introduction. In Lamb, M. E., and Sutton-Smith, B. (eds.), Sibling Relationships: Their Nature and Significance Across the Lifespan. Erlbaum, Hillsdale, NJ.

Lewis, C., and Kiren, G. (1977). You can't have your cake and eat it too: Some considerations of the error term. Psychol. Bull. 84: 1150-1154.

Newman, J. (1991). College students' relationships with siblings. J. Youth Adolesc. 20: 629-644.

Reis, H. T. (1986). Gender effects in social participation: Intimacy, loneliness, and the conduct of social interactions. In Gilmour, R., and Duck, S. (eds.), The Emerging Field of Personal Relationships. Lawrence Erlbaum Associates, Hillsdale, NJ.

Rogers, J. L., and Rowe, D. C. (1988). Influence of siblings on adolescent sexual behavior. Develop. Psychol. 24: 722-728.

Stocker, C., and Dunn, J. (1994). Sibling relationships in childhood and adolescence. In DeFires, J. C., Plomin, R., and Fulkner, D. W. (eds.), Nature and Nurture: During Middle Childhood. Blackwell, Cambridge, MA.

Stoneman, Z., Brody, G. H., and MacKinnon, C. E. (1984). Naturalistic observations of children's roles and activities while playing with their siblings and friends. Child Develop. 55: 617-627.

Vandell, D. L., Minnett, A. M., \& Santrock, J. W. (1987). Age differences in sibling relationships during middle childhood. J. Appl. Develop. Psychol. 8: 247-257.

Wheeler, L., Reis, H. T., and Nezlek, J. (1983). Loneliness, social interaction, and sex roles. J. Personal. Social Psychol. 45: 943-953. 